\title{
The Experimental Analysis of Polymer and Fiber Composite Modified Cement Concrete Experimental Based on Fuzzy Analytic Hierarchy Process
}

\author{
Hongjun Guo ${ }^{1, a}$, Houji Zhang ${ }^{1, b}$, Xiongyi Liang, ${ }^{2, c}$, Junhong Yang ${ }^{3, d}$,Tianxiang \\ $\mathrm{Lu}^{1, \mathrm{e}}, \mathrm{Jian} \operatorname{Ren}^{2, \mathrm{f}}$
}

${ }^{1}$ Hubei Safety \& Environment Technology Institute Co., Ltd. ${ }^{2}$

${ }^{2}$ Wuhan University of Technology

${ }^{3}$ EXi Expressway Administration of Hubei Department of Transportation

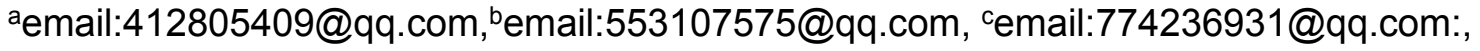

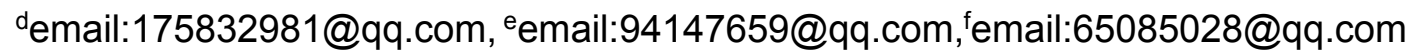

\begin{abstract}
Keywords: fuzzy analytical hierarchy process; orthogonal experiment; polymer and fiber composite modified cement concrete; optimal parameter combination

Abstract: The effect of cement dosage, polymer and fiber content on the mechanical properties and flexural toughness indices of the polymer and fiber composite modified cement concrete has been studied using an orthogonal experiment analysis method. And then the impact of these three factors on the $28 \mathrm{~d}$ flexural-tensile strength, bend-press ratio and flexural toughness of the polymer and fiber composite modified cement concrete has also been investigated by fuzzy analytical hierarchy process. Firstly, the results of this experiment have been obfuscated by a fuzzy math method. Secondly, the weight of each parameter has been calculated by an included angle cosine method. Thirdly, a fuzzy comprehensive evaluation model has been proposed. Finally, the optimal parameter combination of these three have been determined.
\end{abstract}

\section{Introduction}

Many domestic and foreign scholars put forward of the ordinary concrete by polymer emulsion and fiber composite modification, related studies have shown that ${ }^{[1-2]}$, using polymer to modification of fiber cement based materials, can significantly enhance the interface combination between the fiber and cement paste, which can greatly reduce the brittleness of cement base material (mainly from the flexural strength, compression ratio, flexural toughness and other properties characterization), improve the road driving comfort.

Using the fuzzy analytic hierarchy process (ahp) in the fuzzy mathematics, this study on the dosage of cement and polymer emulsion, fiber content through the orthogonal experiment of compound modified evaluation index with fuzzy evaluation, to determine polymer - fiber composite modified cement concrete system of the three factors the best parameter combination.

\section{Test}

Raw Materials.Cement: choose HuaXin P.O 42.5 ordinary Portland cement.Aggregate: choose limestone, is divided into three gears aggregate, among them 1 \# aggregate particle size range of $4.75 \sim 4.75 \mathrm{~mm}, 2$ \# aggregate from $2.36 \mathrm{~mm}$ to $2.36 \mathrm{~mm}, 3$ \# aggregate of $0 \sim 2.36 \mathrm{~mm}$, blending ratio of $1 \#$ : \# 2:3 \# material = 3:1:3. Polymer emulsion: modified carboxylic styrene butadiene latex SD623, its performance indicators are shown in table 1.Fiber: polyester fiber, the relevant properties are shown in table 2. 


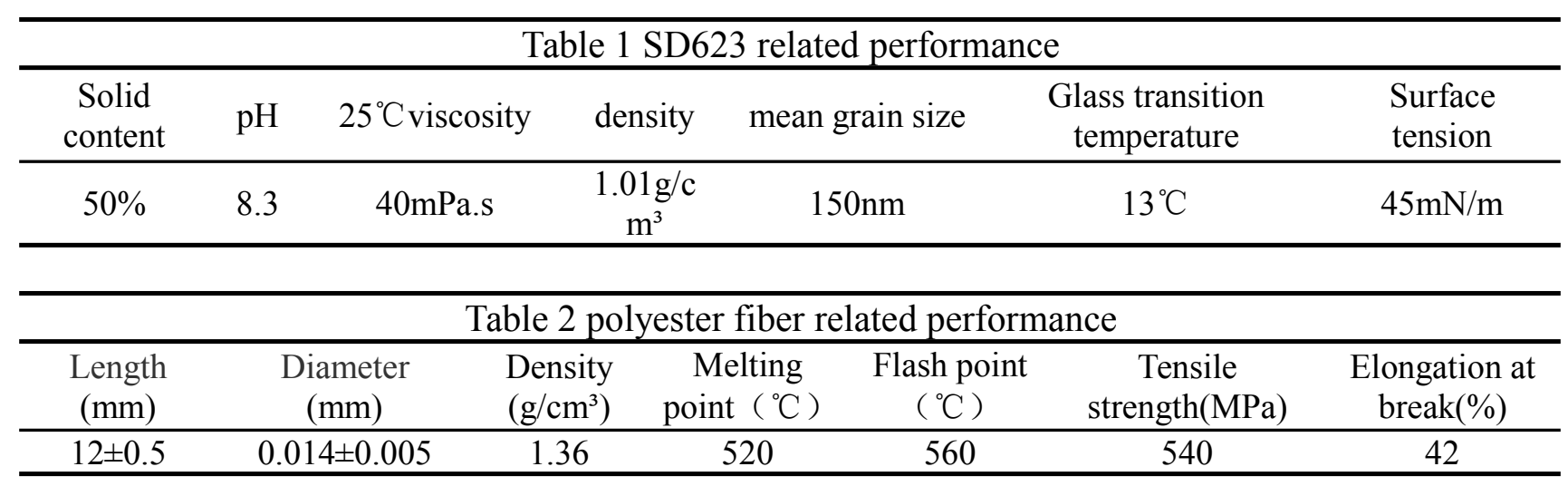

Test Molding Method.Polymer modified cement concrete mechanics performance test: According to the "highway engineering cement and cement concrete experiment regulations"(JTG E30-2005) in T0553-2005 cement concrete cube compressive strength test method and T0558-2005 cement concrete flexural tensile strength test method were determined.

Orthogonal Experiment Design. The experiment on the basis of single factor experiment, mainly from the unilateral cement dosage of A, B dosage of polymer emulsion unilateral and single fiber volume content $\mathrm{C}$, A total of three factors, through fuzzy mathematical evaluation model of polymer modified cement concrete flexural strength of $28 \mathrm{~d}, 28 \mathrm{~d}$ bend toughness, folding ratio, through orthogonal test to evaluate, three indexes were recorded as $\mathrm{X}_{1}, \mathrm{X}_{2}, \mathrm{X}_{3}$.By $\mathrm{L}_{9}\left(3^{4}\right.$ ) orthogonal table to design test, the level of factors are shown in table 3 , the results are shown in table 4 .

\begin{tabular}{|c|c|c|c|c|c|c|}
\hline \multicolumn{7}{|c|}{ Table 3 orthogonal test table level factors } \\
\hline \multirow{2}{*}{ level } & \multicolumn{6}{|c|}{ factors } \\
\hline & \multicolumn{2}{|c|}{ A cement content $\left(\mathrm{kg} / \mathrm{m}^{3}\right)$} & \multicolumn{2}{|l|}{ B emulsion $\left(\mathrm{kg} / \mathrm{m}^{3}\right)$} & \multicolumn{2}{|c|}{ C fiber $(\%)$} \\
\hline 1 & \multicolumn{2}{|c|}{350} & \multicolumn{2}{|l|}{90} & \multicolumn{2}{|c|}{0.08} \\
\hline 2 & \multicolumn{2}{|c|}{325} & \multicolumn{2}{|l|}{80} & \multicolumn{2}{|c|}{0.12} \\
\hline 3 & \multicolumn{2}{|c|}{300} & 70 & & \multicolumn{2}{|c|}{0.16} \\
\hline \multicolumn{7}{|c|}{ Table 4 orthogonal experiments $\mathrm{L}_{9}\left(3^{4}\right)$} \\
\hline Test number & $\mathrm{A} /\left(\mathrm{Kg} / \mathrm{m}^{3}\right)$ & $\mathrm{B} /\left(\mathrm{Kg} / \mathrm{m}^{3}\right)$ & $\mathrm{C} /(\%)$ & $\mathrm{X}_{1}$ & $\mathrm{X}_{2}$ & $\mathrm{X}_{3}$ \\
\hline 1 & 1 & 1 & 1 & 5.23 & 0.130 & 7.312 \\
\hline 2 & 1 & 2 & 2 & 5.06 & 0.125 & 6.383 \\
\hline 3 & 1 & 3 & 3 & 5.04 & 0.117 & 6.189 \\
\hline 4 & 2 & 1 & 2 & 5.43 & 0.140 & 7.696 \\
\hline 5 & 2 & 2 & 3 & 5.37 & 0.137 & 7.181 \\
\hline 6 & 2 & 3 & 1 & 5.39 & 0.130 & 6.614 \\
\hline 7 & 3 & 1 & 3 & 5.08 & 0.144 & 6.207 \\
\hline 8 & 3 & 2 & 1 & 4.96 & 0.137 & 6.189 \\
\hline 9 & 3 & 3 & 2 & 4.99 & 0.130 & 6.085 \\
\hline
\end{tabular}

\section{Application of the Theory of Fuzzy Mathematics Test Data Processing}

Fuzzy Orthogonal Experiment Data Processing.Blurred in the test data with is the principle of treatment process, through the fuzzy matter-element analysis method converts it into corresponding indicators of membership degree ${ }^{[3]}$, conversion formula is as follows:

$$
X_{\mathrm{ij}}^{*}=\left\{\begin{array}{l}
\frac{X_{\mathrm{ij}}}{\max \left(X_{\mathrm{i}}\right)} \\
\frac{\min \left(X_{\mathrm{i}}\right)}{X_{\mathrm{ij}}}
\end{array}(\mathrm{i}=1,2, \cdots \mathrm{m} ; \mathrm{j}=1,2 \cdots, \mathrm{n})\right.
$$


In the formula: $X_{\mathrm{ij}}$ as the index, the measured data of experiment scheme $\mathrm{i} ; ; X_{\mathrm{ij}}{ }^{*}$ as the index, the measured data of experiment scheme $\mathrm{i} j$ conversion value;(1) the values for the bigger the evaluation results more good evaluation index;(2) the smaller type of index numerical evaluation results more good evaluation index; The total number of $m$ as evaluation index; The total number $n$ for test.Using on type of fuzzy orthogonal experiment data processing results are shown in table 5.

\begin{tabular}{|c|c|c|c|c|c|c|}
\hline Test number & $\overline{\mathrm{A}}$ & $\mathrm{B}$ & $\mathrm{C}$ & $\mathrm{X}_{1}^{*}$ & $\mathrm{X}^{*}$ & $\mathrm{X}_{3}{ }^{2}$ \\
\hline 1 & 1 & 1 & 1 & 0.963 & 0.903 & 0.950 \\
\hline 2 & 1 & 2 & 2 & 0.932 & 0.868 & 0.829 \\
\hline 3 & 1 & 3 & 3 & 0.928 & 0.813 & 0.804 \\
\hline 4 & 2 & 1 & 2 & 1.000 & 0.972 & 1.000 \\
\hline 5 & 2 & 2 & 3 & 0.989 & 0.951 & 0.933 \\
\hline 6 & 2 & 3 & 1 & 0.993 & 0.903 & 0.859 \\
\hline 7 & 3 & 1 & 3 & 0.936 & 1.000 & 0.807 \\
\hline 8 & 3 & 2 & 1 & 0.913 & 0.951 & 0.804 \\
\hline 9 & 3 & 3 & 2 & 0.919 & 0.903 & 0.791 \\
\hline
\end{tabular}

The Establishment of the Fuzzy Evaluation Matrix.Calculation of each factor in each level of the average index, namely the first $\mathrm{k}$ level corresponds to a certain factors index of average, computation formula is as follows:

$$
Y_{\mathrm{ij}}=\frac{\sum X_{\mathrm{ij}}^{*}(k)}{n}(\mathrm{i}=1,2, \cdots \mathrm{m} ; \mathrm{j}=1,2 \cdots, \mathrm{n})
$$

In the formula: $Y_{\mathrm{ij}}$ is the average level factors corresponding index; $\mathrm{M}$ number for index evaluation; $\mathrm{N}$ is a factor on the number of levels.

Through the calculation on type, building of all levels under the different factors corresponding to the mean of each evaluation index are shown in table 6.

Table 6 factors under different levels of each evaluation index of average

\begin{tabular}{|c|c|c|c|c|c|c|c|c|c|}
\hline \multirow{2}{*}{$\begin{array}{l}\text { Index conversion } \\
\text { value }\end{array}$} & \multicolumn{3}{|c|}{ A } & \multicolumn{3}{|c|}{ B } & \multicolumn{3}{|c|}{ C } \\
\hline & 1 & 2 & 3 & 1 & 2 & 3 & 1 & 2 & 3 \\
\hline$Y_{1}$ & 0.941 & 0.994 & 0.923 & 0.966 & 0.945 & 0.947 & 0.956 & 0.95 & 0.951 \\
\hline$Y_{2}$ & 0.861 & 0.942 & 0.951 & 0.958 & 0.924 & 0.873 & 0.919 & 0.914 & 0.921 \\
\hline$Y_{3}$ & 0.861 & 0.931 & 0.800 & 0.919 & 0.856 & 0.818 & 0.871 & 0.873 & 0.848 \\
\hline
\end{tabular}

For each factor and its corresponding index of the evaluation set, should be the data normalization processing, normalization processing formula is as follows:

$$
Z_{\text {ij }}=\frac{Y_{\text {ij }}}{\sum_{\mathrm{i}=1}^{n} Y_{\mathrm{ij}}}(\mathrm{j}=1,2 \cdots, \mathrm{n})
$$

In the formula: $Z_{\mathrm{ij}}$ for all levels under the different factors on the results of evaluation indexes should be normalized; $\mathrm{N}$ is a factor on the number of levels.

Through calculation, on the table 8 data normalization treatment, get of all levels under the different factors on the set of evaluation indexes should be normalized as shown in table 7 .

\begin{tabular}{cccccccccc}
\hline \multicolumn{1}{c}{ Table 7 All levels under the different factors on the set of evaluation indexes should be normalized } \\
\hline normalized & \multicolumn{3}{c}{$\mathrm{A}$} & \multicolumn{3}{c}{$\mathrm{B}$} & \multicolumn{4}{c}{$\mathrm{C}$} \\
value & 1 & 2 & 3 & 1 & 2 & 3 & 1 & 2 & 3 \\
\hline $\mathrm{Z}_{1}$ & 0.329 & 0.348 & 0.323 & 0.338 & 0.331 & 0.331 & 0.335 & 0.333 & 0.333 \\
$\mathrm{Z}_{2}$ & 0.313 & 0.342 & 0.345 & 0.348 & 0.335 & 0.317 & 0.334 & 0.332 & 0.334 \\
$\mathrm{Z}_{3}$ & 0.332 & 0.359 & 0.309 & 0.354 & 0.330 & 0.315 & 0.336 & 0.337 & 0.327 \\
\hline
\end{tabular}


The Determination of the Weight Vector.Multiple evaluation indexes in the process of the fuzzy comprehensive evaluation, the determination of the weight vector is the key to determine the content of various factors, in this paper, using the vector included Angle cosine ${ }^{[4]}$, the weight of each evaluation index is constructed.n test plan evaluation indexes on m matrix is as follows:

$\mathrm{A}=\left[\begin{array}{cccc}a_{11} & a_{12} & \cdots & a_{1 n} \\ a_{21} & a_{22} & \cdots & a_{2 n} \\ \vdots & \vdots & \vdots & \vdots \\ a_{m 1} & a_{m 2} & \cdots & a_{m n}\end{array}\right]$

In the formula: $a_{\mathrm{ij}}$ represents $\mathrm{j}$ corresponds to the test program of the $\mathrm{i}$ evaluation index value.

According to the type of evaluation index are obtained as follows:

\begin{tabular}{|c|c|c|c|c|c|c|c|c|c|}
\hline & 5.23 & 5.06 & 5.04 & 5.43 & 5.37 & 5.39 & 5.08 & 4.96 & 4.99 \\
\hline & 0.1 & 0.125 & 0.117 & 0.140 & 0.137 & 0.130 & 0.144 & 0.137 & 0.1 \\
\hline & {$[7.32$} & 6.383 & 6.189 & 7.696 & 7.181 & 6.614 & 6.207 & 6.189 & \\
\hline
\end{tabular}

(1)First of all to establish index, the optimal combination $\mathrm{U}$ and worst evaluation combination V.

$$
\mathrm{U}=(\mathrm{u} 1, \mathrm{u} 2, \cdots, \mathrm{un}), \mathrm{V}=(\mathrm{v} 1, \mathrm{v} 2, \cdots, \mathrm{vn})
$$

$$
\text { In the formula: } u_{i}=\max _{1 \leq j \leq n}\left\{u_{i j}\right\}, v_{i}=\min _{1 \leq j \leq n}\left\{v_{i j}\right\}
$$

This test can be obtained through the type index, the optimal combination $U$ and worst combination evaluation $\mathrm{V}$ :

$$
\mathrm{U}=(5.43,0.144,7.696), \mathrm{V}=(4.96,0.117,6.085)
$$

(2)Construct the test scheme and the relative deviation matrix of $U$ and $\mathrm{V}$

$$
\mathrm{R}=\left(r_{\mathrm{ij}}\right)_{\mathrm{m \times n}}, \Delta=\left(\sigma_{\mathrm{ij}}\right)_{\mathrm{m \times n}}
$$

In the formula:

$$
r_{\mathrm{ij}}=\frac{\left|a_{\mathrm{ij}}-u_{\mathrm{i}}\right|}{\max \left\{a_{\mathrm{ij}}\right\}-\min \left\{a_{\mathrm{ij}}\right\}}(1 \leq j \leq n), \sigma_{\mathrm{ij}} \frac{\left|a_{\mathrm{ij}}-v_{\mathrm{i}}\right|}{\max \left\{a_{\mathrm{ij}}\right\}-\min \left\{a_{\mathrm{ij}}\right\}}(1 \leq j \leq n)
$$

Among them

$\mathrm{i}=1,2 \cdots, \mathrm{m} ; \mathrm{j}=1,2 \cdots, \mathrm{n}$

This test can be obtained through the type index, the optimal combination of $U$ and worst relative deviation matrix of evaluation combination $\mathrm{V}$ :

$$
\begin{aligned}
\mathrm{R} & =\left[\begin{array}{llllllllll}
0.4225 & 0.7872 & 0.8298 & 0.0000 & 0.1277 & 0.0851 & 0.7447 & 1.0000 & 0.9362 \\
0.5185 & 0.7037 & 1.0000 & 0.1481 & 0.2593 & 0.5185 & 0.0000 & 0.2593 & 0.5185 \\
0.2384 & 0.8150 & 0.9354 & 0.0000 & 0.3197 & 0.6716 & 0.9243 & 0.9354 & 1.0000
\end{array}\right] \\
\Delta & =\left[\begin{array}{llllllllll}
0.5745 & 0.2128 & 0.1702 & 1.0000 & 0.8723 & 0.9149 & 0.2553 & 0.0000 & 0.0638 \\
0.4815 & 0.2963 & 0.0000 & 0.8519 & 0.7407 & 0.4815 & 1.0000 & 0.7407 & 0.4815 \\
0.7616 & 0.1850 & 0.0646 & 1.0000 & 0.6803 & 0.3284 & 0.0757 & 0.0646 & 0.0000
\end{array}\right]
\end{aligned}
$$

(3)The weight of each index is established

Firstly calculates $\mathrm{R}$ the row vector ri and the corresponding row vector $\Delta \sigma_{\mathrm{i}}$ Angle cosine, formula is as follows:

$$
\mathrm{M}_{\mathrm{i}}=\frac{\sum_{j=1}^{\mathrm{n}} r_{\mathrm{ij}} \sigma_{\mathrm{ij}}}{\sqrt{\sum_{j=1}^{\mathrm{n}} r_{\mathrm{ij}}^{2} \sqrt{\sum_{j=1}^{n} \sigma_{\mathrm{ij}}^{2}}}}
$$

Through the calculation: $\mathrm{M}=(0.2851,0.4930,0.2934)$

Normalized matrix $\mathrm{M}$ to get the weight vector W:

$$
\mathrm{W}=(0.2661,0.4601,0.2738)
$$


The Establishment of the Evaluation Model.According to the relation with judgment matrix and weight vector,Through the establishment of fuzzy mathematical evaluation model $\mathrm{M}=\mathrm{W} \oplus \mathrm{R}$, to determine each factor's membership degree, including $\mathrm{W}$ after normalizing the weight vector, $\mathrm{R}$ for each factors corresponding to each index set of comprehensive evaluation.From the above formula available:

$$
\begin{aligned}
& \text { A Factors membership } \mathrm{MA}=\mathrm{W} \oplus \mathrm{R}=\left(\begin{array}{lll}
0.2661, & 0.4601, & 0.2738
\end{array}\right) \times\left(\begin{array}{lll}
0.335 & 0.333 & 0.333 \\
0.334 & 0.332 & 0.334 \\
0.336 & 0.337 & 0.327
\end{array}\right) \\
& =(0.3225,0.3483,0.3293) \\
& \text { B Factors membership } \begin{aligned}
\mathrm{MB}=\mathrm{W} \oplus \mathrm{R} & =\left(\begin{array}{lll}
0.2661, & 0.4601,0.2738) \times \quad
\end{array}\right) \quad\left(\begin{array}{ccc}
0.338 & 0.331 & 0.331 \\
0.348 & 0.335 & 0.317 \\
0.354 & 0.330 & 0.315
\end{array}\right) \\
& =(0.3470,0.3326,0.3202)
\end{aligned} \\
& \mathrm{C} \text { Factors membership } \mathrm{MC}=\mathrm{W} \oplus \mathrm{R}=(0.2661,0.4601,0.2738) \times \\
& =(0.3348,0.3336,0.3318) \quad\left(\begin{array}{lll}
0.313 & 0.342 & 0.345 \\
0.332 & 0.359 & 0.309
\end{array}\right)
\end{aligned}
$$

According to the maximum membership degree principle, can be seen from the single factor membership $\mathrm{M}_{\mathrm{A} 2}, \mathrm{M}_{\mathrm{B} 1}, \mathrm{M}_{\mathrm{C} 1}$ was the best blending proportion, namely $\mathrm{A}_{2} \mathrm{~B}_{1} \mathrm{C}_{1}$ as the best process parameter combination.

Model to Judge the Result Analysis.Evaluation result is obtained by fuzzy mathematical evaluation model by:

(1) After polymer mixed with the hydration of cement in the cement paste gradually form a continuous mesh film, which have the effect of cementation and filling small gap, the toughness of cement base material modification, the modification effect and is closely related to ratio of poly ${ }^{[5]}$.

(2) The fiber under this system, due to the effect of modification of the polymer to cement paste, makes the connection fiber and cement paste closer, improved fiber and slurry interface transition zone, micro and macro defects, to further fiber toughening crack resistance effect.

\section{Conclusions}

(1)In this paper, using the orthogonal method of polymer - fiber composite modified cement concrete experiment design, and using the fuzzy mathematical model analytic hierarchy process to analyze the test results, and effectively make up for the traditional orthogonal experiment data analysis method is easy to appear the lack of local optimal solution.

(2)Through the mathematical model of fuzzy evaluation, The $28 \mathrm{~d}$ flexural strength, folding compressive and flexural toughness of three indexes under different weight coefficient, the dosage of cement and polymer emulsion, the best combination of fiber content, the dosage of cement 325 $\mathrm{kg} / \mathrm{m}^{3}$, polymer emulsion dosage of $90 \mathrm{~kg} / \mathrm{m}^{3}$, fiber volume content $0.08 \% / \mathrm{m}^{3}$.

(3)This article mainly from the Angle of the material itself modification effect were studied, as pavement material, the stand or fall of its specific performance is needed from including the abrasion resistance, permeability resistance, durability, performance indicators for further evaluation.

\section{Acknowledgements}

This work was financially supported by the National Natural Science Fund (51402226) and Hubei province transportation science and technology project (20130113).

\section{References}

[1]Zhao Shuai, lyndon, cao Yang, tian ying.Polypropylene fibers and polymer emulsion on cement mortar properties influence [J]. Journal of building materials.2007,6(10):648-652.

[2] Gao Jianming Dong Xiang, ya-qing jiang, Hu Aiyu. Polymer emulsion on the mechanical 
behavior of fiber reinforced lightweight aggregate concrete influence [J]. Journal of southeast university, 2006, 4 (2) : 288-292.

[3]Xu Dong good tong-jiang fan, Chen Fugui Jia Jingpeng. Fuzzy orthogonal design method in the application of asphalt mixture test $[\mathrm{J}]$. Journal of chongqing jiaotong university: natural science edition, 2007 (8) : 60-64.

[4]Li Bainian. Multi-objective decision-making in a kind of objective weight determination method [J]. Journal of management and administration, 2002 (5) : 36 to 39.

[5]xue fang. Paving molding of polymer modified cement concrete pavement functional material research. Wuhan: wuhan university of technology $\mathrm{PhD}$ thesis. 2010, 4. 